\title{
The Commodification of Rurality and its Sustainability in the Jike Area, Yokohama City, the Tokyo Metropolitan Fringe
}

\author{
KIKUCHI Toshio \\ Department of Tourism Science, Tokyo Metropolitan University; Minami-Ohsawa, Hachiohji, Tokyo, Japan. \\ E-mail: kikuchan@tmu.ac.jp
}

Received September 4, 2009; Accepted December 8, 2009

\begin{abstract}
In this paper the author focuses on rurality as an option of urbanity in the Jike area, Yokohama city, the Tokyo metropolitan fringe, and discusses the sustainable commodification of rural space in the area. Following his discussion, the author identifies some conditions that supported the commodification of rurality and their interaction in the outer fringe of the Metropolitan area. In the Jike area, the decrease in area of rural forests (satoyama) has led to the decline of rural landscape; the development of affordable housing lots in the outer fringe and the continuous inflow of urban residents into the newly developed areas have led to serious conflicts between rural and urban land uses. Recently however, activities that aim at recreating rurality, such as conservation of rural forests, have been promoted as a means to mitigate such conflicts, and to develop these areas as nodes of rurality and urbanity. Thus, the perpetuation of rurality has been assured by the sustainable relationships between rurality and urbanity. The conservation of rurality facilitates the commodification of rural spaces, a process which has played an important role in developing rurality-based tourism.
\end{abstract}

Key words rurality, rural forests, conservation activities, outer fringe, commodification, rural tourism

\section{Introduction}

The Tokyo metropolitan fringe is divided into the inner and outer fringes by rural and urban land use competition. The inner fringe is characterized by land in the advanced stages of transition from rural to urban land uses, dominant location of urban-oriented function and land subdivision (Bryant et al. 1982; Ilbery 1985; Bryant and Johnston 1992). Particularly, the inner fringes of the Tokyo metropolitan area have been characterized by strong conflicts between rural and urban land uses, where rural land use has tended to be drastically reduced since the period of high economic growth in Japan (Kikuchi and Obara 2004). At the time, most farmers in the inner fringe reduced their investment in agriculture and their labor intensity of agricultural production, or left their farmland idle in anticipation of rising land prices; as a consequence, the conversion of farmland into urban land uses such as residential and commercial lots progressed rapidly. (Kikuchi and Takatori 1998; Kikuchi and Tsutsumi 1998).

On the other hand, the outer fringe is characterized by an area where despite the domination of rural land use in the landscape, the infiltration of urban-oriented elements is clearly reflected in the increase of part-time farms and the development of extensive farming (Kikuchi and Moran 1990; Kikuchi 1994; Kikuchi 2002). In the outer fringes of the Tokyo metropolitan area, agricultural land use has been more or less perpetuated, and played an important role in restructuring rural and residential spaces. Agricultural land use is a fundamental element of the rural space and landscape, and is characterized by its productive functions of crop growing and agricultural activities. With the progress of urbanization, however, the economic function of agricultural land has diminished in comparison with urban land use, and farmland has been maintained for its multi-functional land uses with the emphasis on other functions such as landscape and health amenity, green spaces and recreation opportunities (Kikuchi and Takatori 1998; Takatori 2000; Kikuchi and Obara 2005).

The analysis of land use changes in the outer fringe used to be one of the important themes of rural geography; recently, restructuring of rurality has become the new focus of research, as one of the most challenging contemporary issues (Murdoch and Pratt 1993; Marsden 1996; Bowler et al. 2002). In this paper the author focuses on rurality as an option of urbanity in the outer fringes of the Tokyo metropolitan area, and discuss about the sustainable commodification of rural landscape and 
space as a means of rural restructuring. Following this discussion, the author attempts to identify some of the conditions which supported the commodification of rurality in the outer fringe, and their interaction.

Meanings of rurality are often associated with the character of rural space, as areas where rural communities exist and rural activities occur. In these areas, environmental and economic aspects were noted expressions of their character and community locations with reference to agricultural activities and production. Because agricultural activities and production have declined with the advance of urbanization, rurality has generally receded due to the encroachment of urban land use. In the outer fringe of Tokyo metropolis, however, rurality has been maintained and recreated with the restructuring of some basic elements of the rural space (Kikuchi et al. 2002, 2006). Therefore, rurality consists of agricultural activities and production, rural land use and landscape, and farms and their community. The interrelation among these elements plays an important role in restructuring rurality and in the process of its commodification (Cloke 1993; Halfacree 1995; Takatori 1998; Liepins 2000).

\section{Changes in Rural Land Use in the Northwestern Part of Yokohama City}

The Jike area was chosen as a case study for the present research. It is located in the northwestern part of Yokohama city, and is situated in the southwestern suburbs of Tokyo metropolis, 30 kilometers away from the metropolitan centre (Figure 1), on the boundary between Tokyo metropolis and Kanagawa prefecture. This geographical situation is suitable for suburbanites to commute to the Tokyo metropolitan center by train and for the construction of affordable houses. Because one of the foci of this research is rural land use changes in and around the Jike area, the analysis is based on two land use maps of the area created from available grid data of one square kilometer: one for 1974, representing the end of the period of high economic growth and the second for 1994 as the period following the burst of the bubble economy.

\section{Land use in around the Jike area in 1974}

The author prepared the map of Figure 2-a) to discuss the distribution of rural land use and its characteristics in and around the Jike area in 1974. According to this figure, rural land use of paddy and upland fields and forests was maintained as green space in spite of the continuous expansion of land in residential, industrial, commercial and business uses, from the metropolitan centre to its outskirts because of increasing population and improving traffic infrastructure. Although the expansion of urban land use has been more remarkable within a 30 kilometers radius from the metropolitan centre, small areas of urban land use were also dispersedly developed on the outer fringes, ignoring the city or regional planning. This dispersion not only caused the urban sprawl, but also accelerated the expansion of continuous urban land use from the metropolitan centre. In the northwestern part of Yokohama city, diluvial uplands as terraces and gentle hill slopes between uplands and valley lowlands are distributed widely, and they allow easy conversion into urban land use such as residential and industrial uses. Actually, built up areas were extended with the conversion from non-urban into urban land uses on diluvial uplands and gentle hill slopes along some railroads and main roads, and around railroad stations. This fact suggests that the conversion from non-urban to urban land uses is supported by the availability of suitable land and the accessibility to the metropolitan centre.

Regarding agricultural land use in and around the Jike area, its distribution was characterized by a mosaic of small fields and dispersed patterns. Upland fields including orchards and paddy fields were generally distributed on diluvial uplands and valley lowlands respectively. Traditionally, each farm with 1.0 to 1.5 hectares of farmland in three to five parcels around the rural settlement is located on the terrace and gentle hill slopes about 200 meters away from the settlement, and on valley lowlands. These parcels of farmland were diversely used according to the distance from the settlement. Generally speaking, vegetables for family subsistence and sale were grown under a double cropping system on farmlands adjacent to the rural settlement; wheat, barley and potato on farmlands away from the rural settlement; orchard trees on gentle hill slopes and sandy uplands, and rice under a one cropping system on paddy fields of valley lowlands. This agricultural land use was suitable for the small scale and dispersed pattern of landholding, which were traditionally maintained, for the equality of the land tenure, and the minimization and dispersion of risk such as natural disaster and market price slump. As a whole, agricultural land use tended to diminish due to the competition with urban land use in the suburbs of the Tokyo metropolitan area. In and around the Jike area, however, agricultural land use was still maintained and continued to play an important role in producing vegetables and fruits for local markets. 


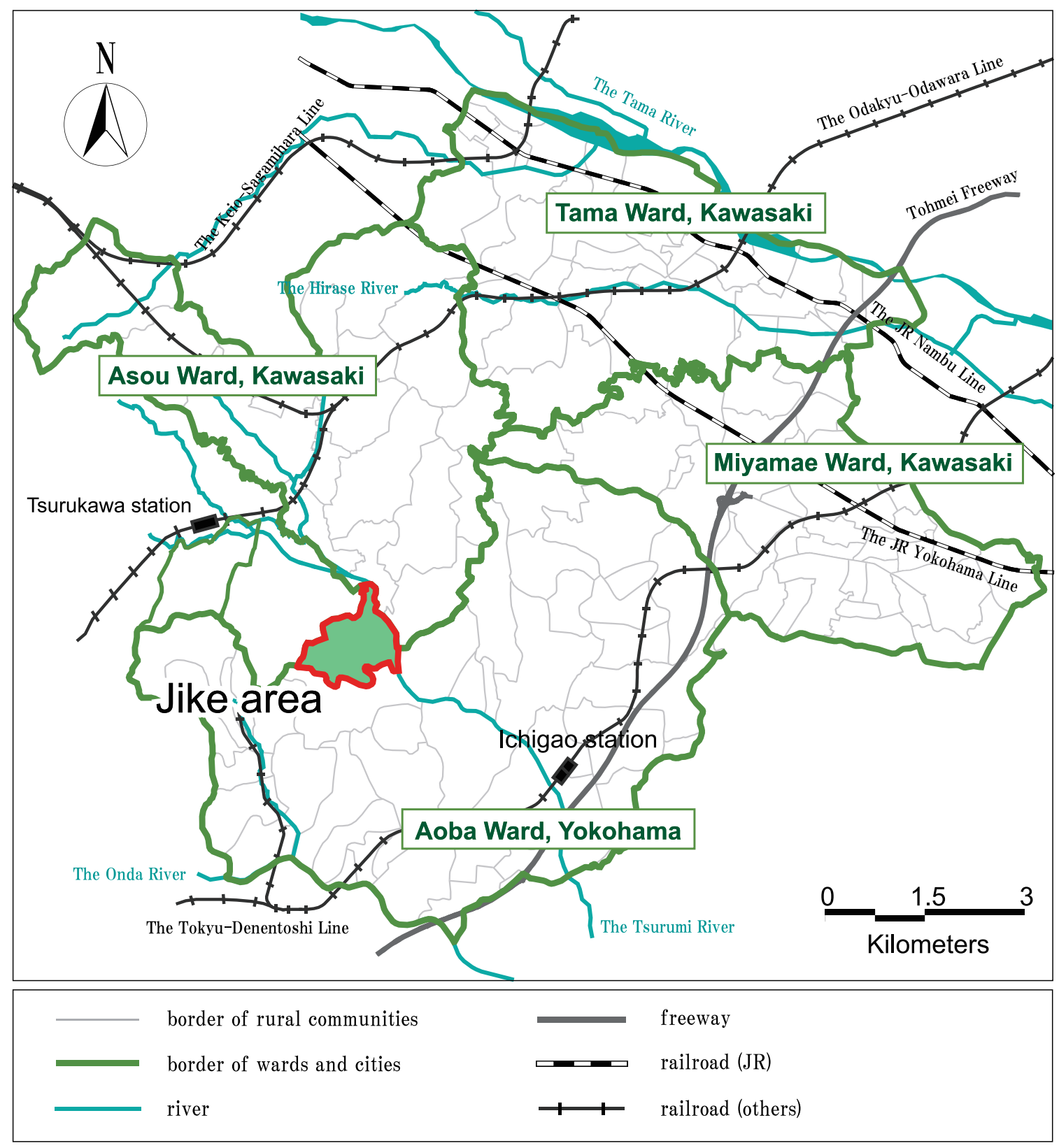

Figure 1 The situation of the Jike area as a study area.

On the other hand, forest land use, which is a main element of rural landscape along with agricultural land use, also remained as rural forest (satoyama) in and around the Jike area. Forest land use was generally distributed on the terrace and hilly lands around paddy and upland fields. Rural forests traditionally played an important role in producing compost for cultivation of vegetables and potatoes, and it was necessary for each farm to hold a forest acreage equivalent to more than three times the acreage of upland fields for producing compost. Since the 1970s, however, this role of forests has declined with the use of chemical fertilizers and a shortage of labor for forest maintenance such as weeding and forest undergrowth clearing, so that rural forests have been reduced as they changed hands. Because most farmers could not pay the expensive inheritance tax, they had to sell part of their rural forests for paying taxes. Consequently, the decrease of forest land use led not only to environmental issues such as the extinction of plants, animals and insects indigenous to rural forests, but also to a decline of traditional rural life.

\section{Land use in and around the Jike area in 1994}

In the period after the bubble economy burst, the conversion from rural to urban land uses has been more active in spite of low economic growth and land price depreciation, because the construction of houses has been prominently developed in metropolitan suburbs stimulated by high housing demand, low land prices and cheaper transportation costs. In order to explain 
a) 1974

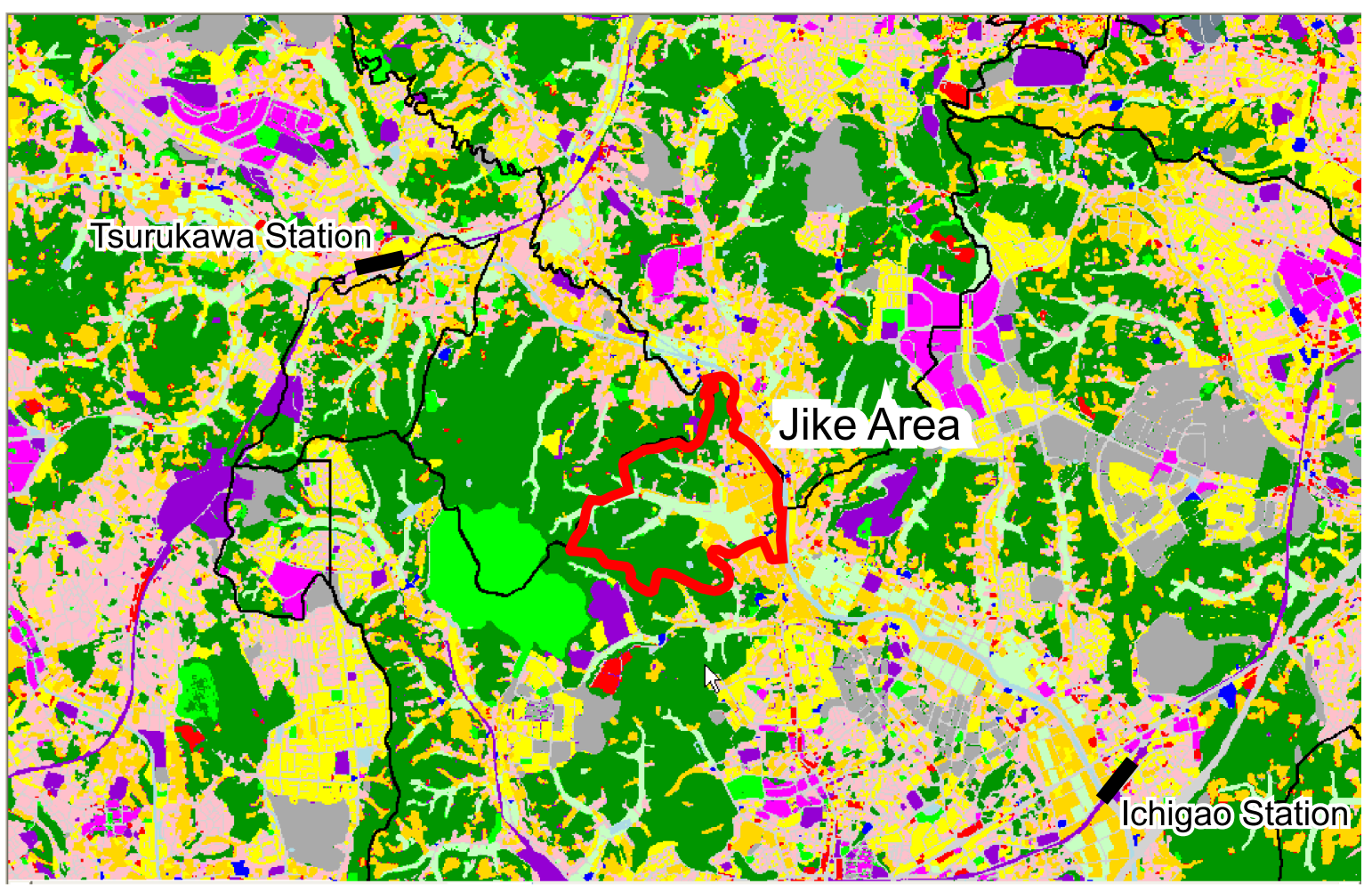

b) 1994

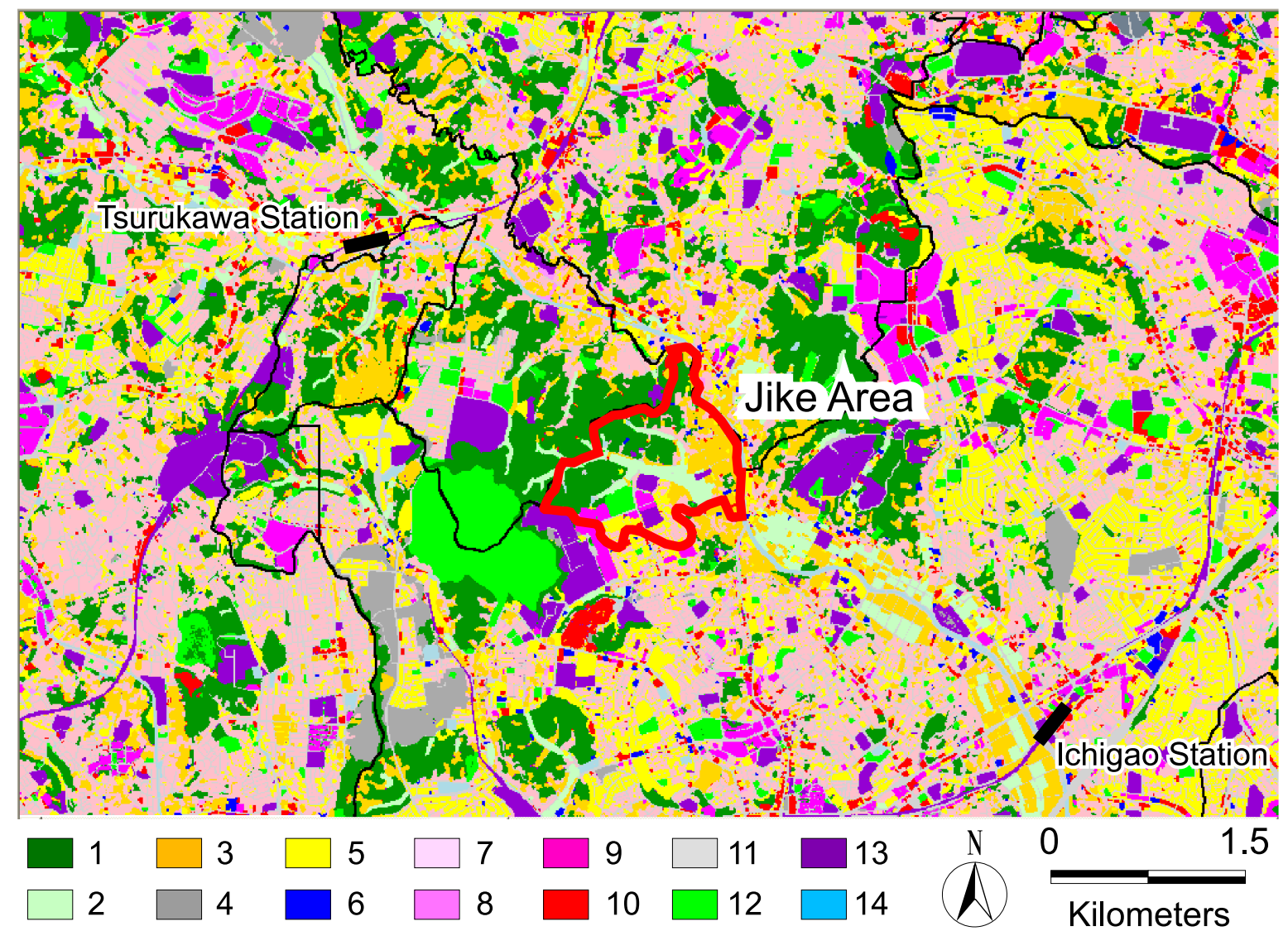

Figure 2. Land use in and around the Jike area, 1974 and 1994.

1: Forests and wastelands, 2: paddy fields, 3: upland fields (including orchards), 4: plots under development, 5: vacant plots, 6: industrial uses, 7: low rise residential uses, 8: concentration of low rise residences, 9: medium and high rise residential uses, 10: commercial and business uses, 11: roads, 12: parks and open spaces, 13: public spaces and facilities, 14: rivers and waters. Sources: National Land Information System. 
the present-day rural land use in and around the Jike area, a land use map showing the situation in 1994 was made (Figure 2-b)). As shown in the map, rural land use diminished from the 1970s, because urban land use has been continuously expanded from the metropolitan centre to the outer suburbs since the period of high economic growth. The dispersion of urban land use and the urban sprawl accelerated the competition with rural land use, so that urban land use is linearly expanded along main transportation networks with the conversion from rural to urban land uses. Although the conversion is more active on diluvial uplands and gentle hill slopes in and around the Jike area, the process is also present along valley lowlands because of great demand of land for urban uses. This fact suggests that the conversion from non-urban to urban land uses was supported by the availability of suitable land and the accessibility to the metropolitan centre.

Turning to rural land use, small areas of agricultural land use have been maintained as productive green land in and around rural settlements. Under the circumstances of progressive urbanization, agricultural land use is fragmentarily maintained on fertile diluvial uplands, where small scale vegetable growing for local markets and farm shops has been developed since the 1990s. The policy of productive green land gives preferential tax treatment for farms which continue to hold their farmland for more than 30 years. Additionally, most of vegetable growing fields in the area were designated as productive green land, so that the Act of Productive Green Land played an important role in maintaining farmlands, and temporarily controlled the decrease in farmland in the 1990s. As this policy was enforced, farmland was viewed as fulfilling more various functions such as amenity, nature conservation and disaster prevention in addition to its productive function.

Although the basic pattern of agricultural land use in the area has consisted of upland fields and forests on the terrace, orchard fields on gentle hill slopes and sandy uplands, and paddy fields on valley lowlands, this pattern has gradually shifted into the combination of upland and orchard fields despite the maintenance of agricultural land use since the 1980s. Similarly, the function of agricultural land use has been distinctly characterized as suburban farming since the 1990s. For example, vegetable growing accounts for the largest acreage among agricultural land use, and most of its produce is shipped to local markets and farm shops. Cultivated vegetables were not only those traditionally grown in the area as cabbages, radishes and Chinese cabbages, but also carrots, onions, and broccoli, so that vegetable production has been diversified. Along with vegetable growing, orchard fields on gentle hill slopes and sandy uplands were fragmentarily maintained with the branding "hama-nashi" pears. In terms of paddy fields, their acreage has been considerably reduced since the 1970s, and rice has been mainly grown as a subsistence crop.

Forest land use in and around the Jike area has continuously decreased with the development of housing lots since the 1970s. Actually, forest land use near railroad stations rapidly receded with the construction of a large scale housing complex from the 1970s to the 1980s. Because the economic function of forest land use was reduced with the decline of forestry and forest resource utilization, and because forests were not protected by the preferential land tax system as productive green land, farmers tended to sell forest lands for paying taxes and for profit from the 1970s to the 1980s. Since the 1990s, rural forests on the terrace and near rural settlements have been maintained by conservation groups of forest and natural environment, which were organized by farmers and urban residents. According to these conservation activities, most of rural forests were maintained as valuable green spaces. Therefore, forests are generally preserved on the terrace and hilly lands around valley lowlands and rural settlements, with a shift from their productive function to landscape amenity, the symbol of good residential environments. In the northwestern part of Yokohama city, the Jike area is a conservation area of rural forests, maintained by a group of farmers and urban residents. Their activities greatly contribute to the conservation of ecosystems and biodiversity around rural forests.

\section{The Maintenance of Rural Land Use and Agricultural Management in Jike Area}

\section{The change in agricultural land use and management}

In the following chapter, the author attempts to examine the change in agricultural land use and management with the development of urbanization in the Jike area. Table 1 shows the changes in the number of farms, the acreage of farmlands and main sectors of the agricultural income in the Jike area. According to this table, farmland acreage under management in 1970 and 2000 amounted to 28.4 and 18.2 hectares, so that agricultural land use has been partly maintained since the 1970s in spite of extreme urbanization. In terms of agricultural land use, paddy field acreage decreased from 10.6 hectares in 1970 to 6.4 hectares in 2000 , because the 
Table 1. Changes in farms, the acreage of farmlands and main sectors of the agricultural income in the Jike area

\begin{tabular}{|c|c|c|c|c|c|c|c|c|c|c|}
\hline \multirow{2}{*}{ Year } & \multicolumn{4}{|c|}{ The number of farms (households) } & \multicolumn{4}{|c|}{ Farmland acreage under management (ha) } & \multicolumn{2}{|c|}{$\begin{array}{l}\text { The main sectors of } \\
\text { agricultural income of } \\
\text { farms (households) }\end{array}$} \\
\hline & Total & $\begin{array}{l}\text { Full-time } \\
\text { farms }\end{array}$ & $\begin{array}{l}\text { Part-time } \\
\text { farms }\end{array}$ & $\begin{array}{c}\text { The rate of } \\
\text { old aged } \\
\text { farms }\end{array}$ & Paddy field & $\begin{array}{l}\text { Upland } \\
\text { field }\end{array}$ & Orchard & Total & Vegetables & Fruits \\
\hline 1970 & 32 & 11 & 21 & 21.0 & 10.6 & 16.5 & 1.3 & 28.4 & 7 & 1 \\
\hline 1975 & 35 & 4 & 31 & 14.3 & 10.2 & 14.7 & 2.8 & 27.7 & 8 & 1 \\
\hline 1980 & 36 & 2 & 34 & 25.0 & 9.2 & 11.1 & 4.6 & 24.9 & 7 & 4 \\
\hline 1985 & 36 & 5 & 31 & 34.5 & 8.5 & 9.9 & 4.5 & 22.9 & 5 & 5 \\
\hline 1990 & 35 & 3 & 32 & 54.5 & 8.1 & 10.8 & 4.3 & 23.2 & 7 & 7 \\
\hline 1995 & 32 & 1 & 31 & 68.6 & 8.0 & 11.1 & 4.3 & 23.4 & 14 & 8 \\
\hline 2000 & 31 & 3 & 28 & 75.8 & 6.4 & 7.2 & 4.6 & 18.2 & 7 & 9 \\
\hline
\end{tabular}

Sources: Agricultural census.

environment of rice growing has deteriorated due to the expansion of residential development, the dilapidation of spring water irrigation, and aging farmers. Although upland field acreage also decreased from 16.5 hectares in 1970 to 7.2 hectares in 2000 , it has been maintained under vegetable cultivation for the local market or farm shops as suburban farming since the 1970s. The number of farms relying mainly on agricultural incomes from vegetable cultivation was relatively stable based on the successful branding strategy of "hama-yasai" vegetables for local markets. On the other hand, orchard acreage increased from 1.3 hectares in 1970 to 4.6 hectares in 2000, due to the same branding strategy ("hama-nashi"pears); the number of farms relying mainly on agricultural incomes from fruit cultivation also increased from one in 1970 to nine in 2000.

In the Jike area, the number of full-time farms decreased from eleven in 1970 to three in 2000, while the number of part-time farms increased from 21 in 1970 to 28 in 2000. These changes led to the decrease in farm population with the development of mixed rural-urban landscape and society. The increase in part-time farms reflected the fact that the Jike area has good accessibility to the metropolitan center, and that many successors of farms were engaged in off-farm jobs, commuting to the metropolitan center. Therefore, the percentage of farms managed by elderly farmers (over 60 years old), has increased since the 1980s. In 2000 it was 75.8 percent, which reflects the aging of farmers following the process of suburbanization of farming. Although the decrease in full-time farms and the increase of part-time farms are one of the general characteristics in the urban fringe, in the Jike area, the most important regional characteristic of rural changes is that the number of farms has stayed constant since the 1970s (Table 1). As a whole, farms in the Jike area can be classified into two types: full-time farms and part-time farms.

\section{Agricultural land use and management in a full-time farm}

Figure 3 shows agricultural land use of a sample fulltime farm; the farm manages 1.5 hectares of its own farmland, dispersed in nine parcels, situated relatively close to the main house. On the closest plots of 20, 10 and 10 ares around the farmhouse, tomatoes and cucumbers are grown as cash crops in greenhouses. The rest of the land surrounding the farmhouse $(30,30,10$ ares) is used for pears (Kousui and Housui varieties), vegetables and beans for local markets and the farm shop respectively. Actually "hama-nashi" pears and "hamayasai" vegetables have become important cash crops for the farm shop, which has been located next to the farmhouse since the 1980s. On the remaining plots (of 20 and 40 ares), 200 meters away from the farmhouse, "hama-yasai" komatsuna and rice as a self-support crop are cultivated. As a whole, a small amount of diversified vegetables, beans and pears are grown on the farm, where the household head and his wife are mainly engaged in general farming, and his successor and daughter-in-law are mainly engaged in horticulture.

Although a full-time farm chosen as a sample in the Jike area is also typically characterized by the combination of general farming with horticulture, a common characteristic for full-time farms is to cultivate a small amount of diversified crops, carefully managed. Because it is difficult to get much income from the cultivation of a small amount of diversified crops, this farm started to grow vegetables in greenhouses taking advantage of the 


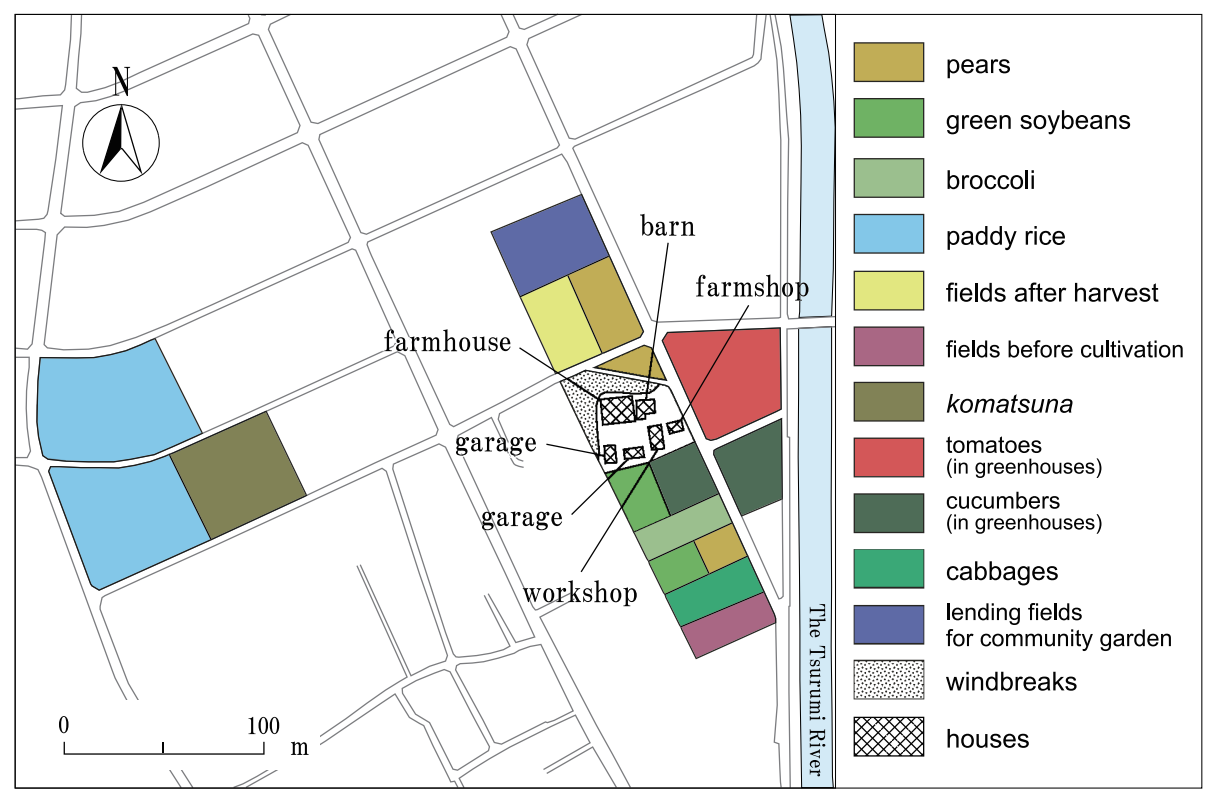

Figure 3. Land use in a sample of full-time farms in the Jike area, June, 2007. Sources: Field survey and interview.

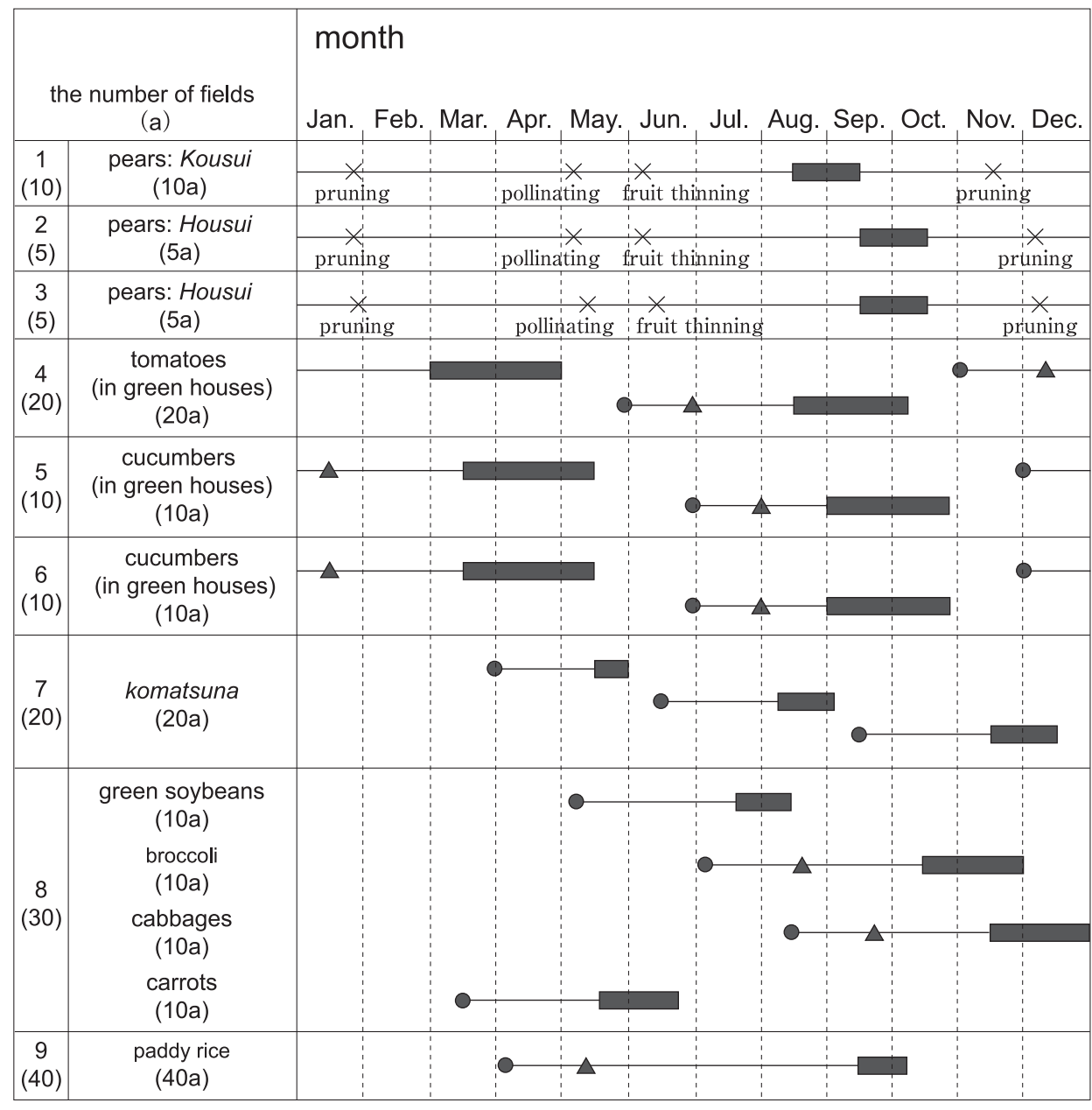

- seeding

$\Delta$ planting

$\times$ pruning, pollinating, fruit thinning

Figure 4. The calendar of cultivation in a sample of full-time farmers in the Jike area, 2007. Sources: Field survey and interview.

existence of a successor willing to continue farming. According to the calendar of cultivation on this farm
(Figure 4), agricultural labor is evenly distributed throughout the year, and excepting the short peak of 
agricultural labor, the borderline between agricultural season and off-season is not clear. Regarding the younger farmers (the successor and his wife), the distribution of their agricultural labor throughout the year is centered on vegetable production for local markets in greenhouses, under a double cropping system. Tomatoes, planted in May and November, were harvested in August to October, and March to April, respectively. Cucumbers, planted in June and December, were harvested in September to October, and March to May, respectively. Orchards are cooperatively managed by the two generations of farmers. Pears were harvested in August to October; pruning occurred in November and January, pollination in May and fruit thinning in June.

Regarding the elderly farmers, the distribution of their agricultural labor throughout the year is centered on vegetable and bean production for their farm shop near the upland fields, and on rice production for their subsistence in paddy fields. Their vegetable and bean production is characterized by the cultivation of a small amount of diversified crops. The crop rotation system of vegetable-bean such as broccoli, cabbages, carrots and green soybeans plays an important role in maintaining soil fertility and preventing soil degradation, without much use of chemical fertilizer and pesticide. Particularly, komatsuna is an important production for the farm shop, due to demand from urban residents in the area for fresh, delicious and healthy vegetables in season (Figure 5). Komatsuna, planted in March, June and September, were harvested in May, August, November to December under a multiple cropping scheme. The vegetable production for farm shops is suitable for elderly farmers, because it is not very demanding (excepting the peak period of agricultural labor).

\section{Agricultural land use and management in a part-time farm}

On the other hand, similar to other urban fringes, part-time farming is the general type of agricultural management in the Jike area. Figure 6 shows the agricultural land use on a part-time farm chosen as a sample. The farm manages 0.8 hectares of its own farmland, dispersed in four parcels, all situated close to the main house of this farm. On the plot of 25 ares around the farmhouse, a small amount of "hama-yasai"

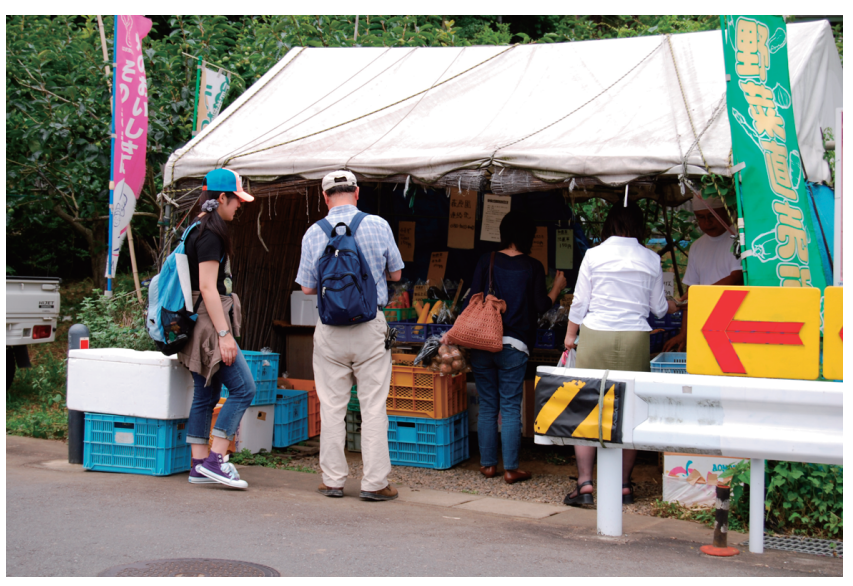

Figure 5. A farm shop in the Jike area. Taken by the author, July 2009.

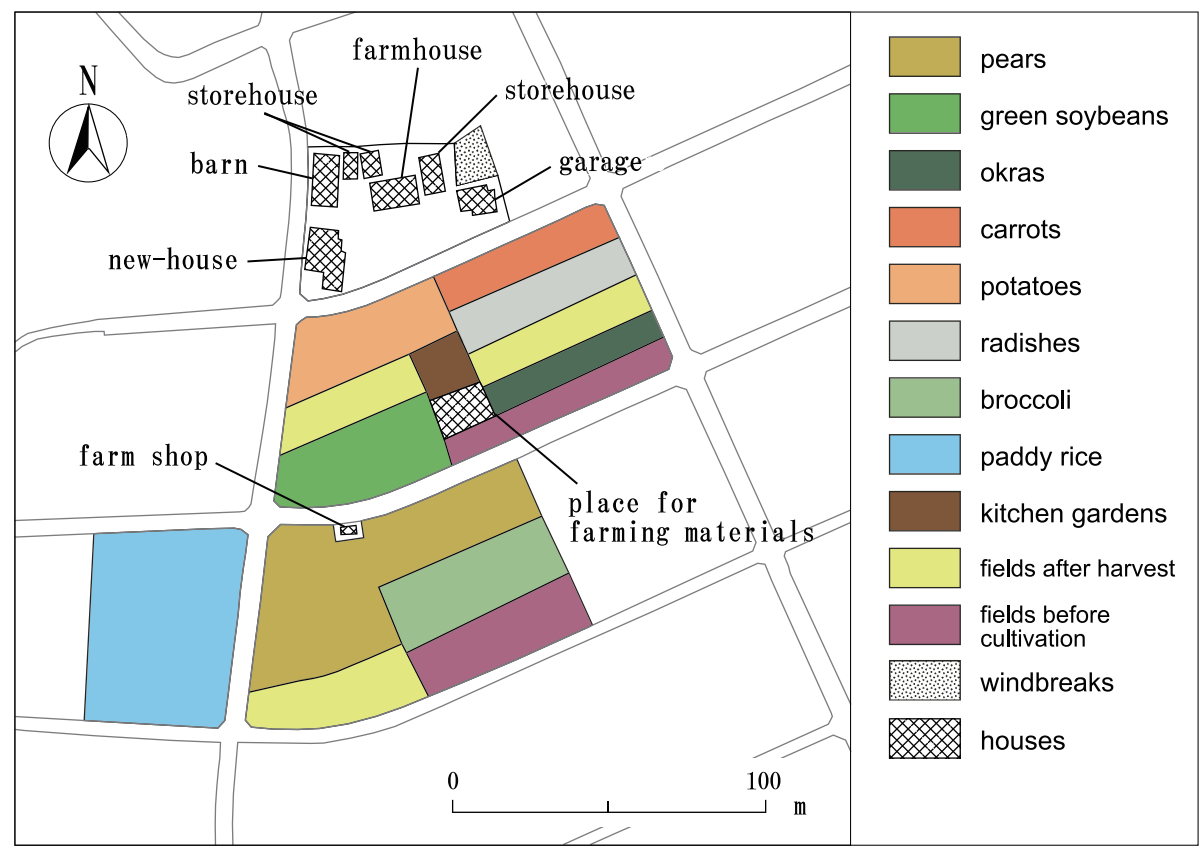

Figure 6. Land use in a sample of part-time farms in the Jike area, June, 2007. Sources: Field survey and interview. 
green soybeans, okras, carrots, potatoes and radishes are grown under a multiple cropping system and sold at the farm shop. On the other plots around the farm shop, pears (Kousui and Housui varieties) are cultivated on 20 ares for the farm shop and as "pick your own" orchards. Actually, the system of "pick your own" plays an important role in saving labor force and attracting rural tourism around this farm. On the remaining plots of 20 and 15 ares, 100 meters away from the farmhouse, "hamayasai" broccoli and rice for family subsistence are grown. As a whole, the small amount of diversified vegetables and pears are cultivated for the farm shop on this farm, where the household head, his successor and daughterin-law are mainly engaged in off-farm businesses, and his wife is mainly engaged in farming.

Common characteristics of part-time farms in the Jike area are: the cultivation of subsistence crops by the elderly farmers, as well as the cultivation of a small amount of diversified crops for farm shops under a carefully managed crop rotation system. Because it was difficult to ship such a small amount of various crops to the large scale metropolitan markets, the above-mentioned farm has managed the farm shop for selling vegetables and fruits to urban residents since the 1990s. This farm shop is suitable for selling a small amount of various crops as a means to get much needed agricultural income, but also as a means for farmers to continue living useful lives. This system of agricultural production is suitable for the elderly farmers, since, according to the calendar of cultivation on this farm (Figure 7), agricultural labor is evenly distributed throughout the year, except the peak season.

A similar case is that of a different part-time farm, where komatsuna ( 5 ares) and green beans ( 5 ares) were planted in March and April, and harvested in May and June respectively. Along with komatsuna and green beans, vegetables such as egg plants (5 ares), okras (5 ares), carrots ( 5 ares), radishes (5 ares), onions (5 ares), Chinese cabbages ( 5 ares), green soybeans ( 5 ares) and potatoes ( 5 ares) were successively grown under a system of multiple

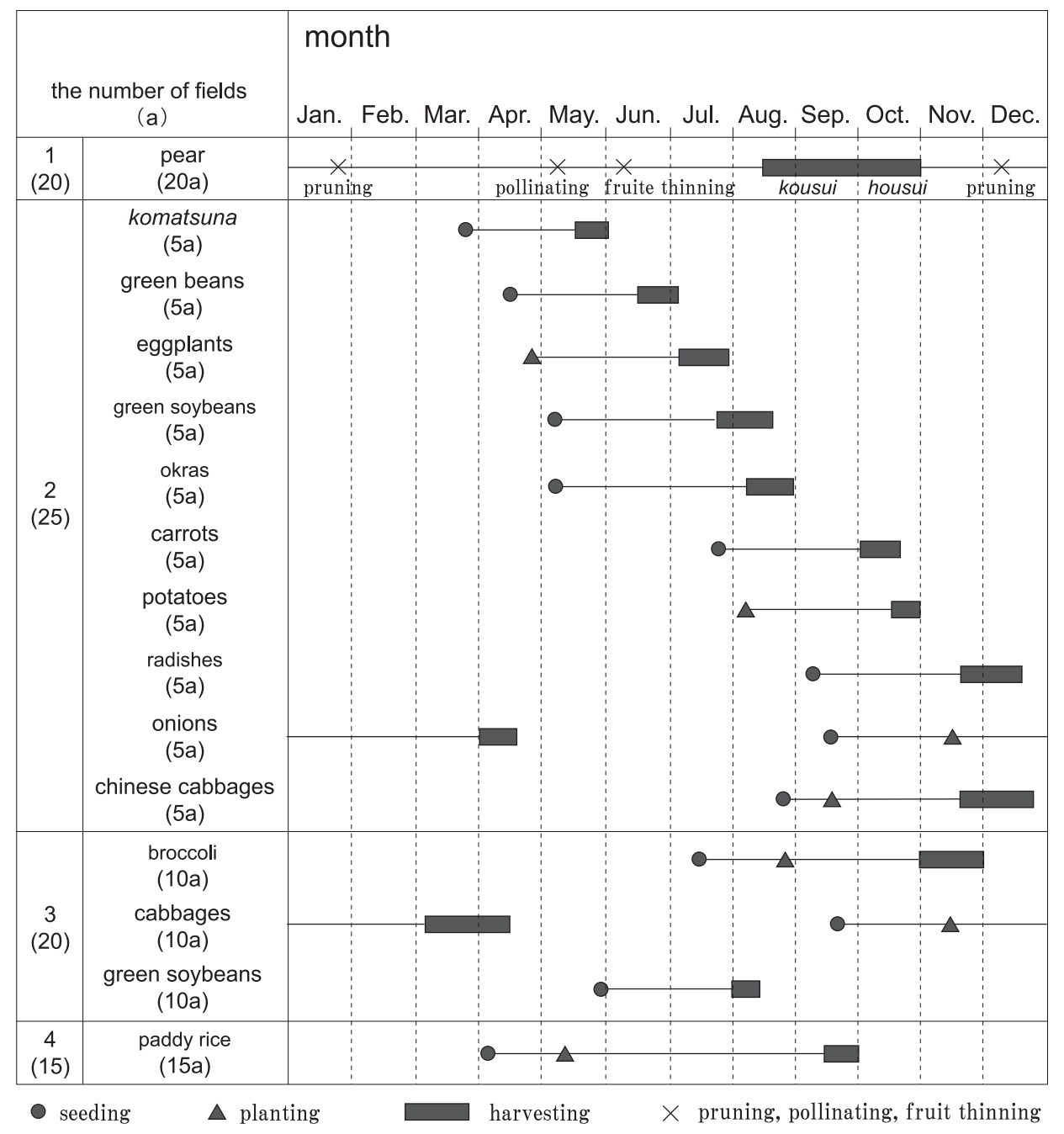

Figure 7. The calendar of cultivation in a sample of part-time farmers in the Jike area, 2007. Sources: Field survey and interview. 
cropping throughout the year. Similarly, the third sample farm cultivates broccoli (10 ares), cabbages (10 ares) and green soybeans (10 ares) under the same system of multiple cropping throughout the year (Figure 7). On the other hand, elderly farmers grow pears for the farm shop and rice for their subsistence. As a whole, the distribution of their agricultural labor force throughout the year is centered on vegetables and pear growing for their farm shop. Farm shops play an important role in providing fresh and healthy vegetables and pears for visitors to the Jike area, where rural landscape such as agricultural land use, rural forest and valley lowlands are the main attractions for rural walking and tourism. Direct sale of vegetables and pears through farm shops is available for small amounts of diversified crops in season. This farming system and management are suitable for part-time farms, elderly farmers and small scale farms.

\section{The Conservation Activity of Rural Spaces in the Jike Area}

In spite of the conflict between rural and urban land uses, local farming of hama-yasai and hama-nashi has been perpetuated in the Jike area since the 1980s. The maintenance of local farming practice was supported by the conservation of rural forests and valley lowlands as traditional rural landscape, and as ecological bases of agricultural production and crop growing. The traditional rural landscape conserved by farmers comprised rural settlements, the forests behind them, and upland and paddy fields around them. Particularly, rural forests played an important role in producing fallen leaves as compost for vegetables and potato cultivation, in supplying water to valley lowlands for the cultivation of paddy rice and in the conservation of biodiversity. Besides economic and ecological roles, rural forests were conserved as the grove of the local deity, a spiritual symbol for rural residents. Although rural forests used to have many functions in the rural space, these have been reduced with the progress of urbanization and with the generational change as a turning point. Since the 1980s, rural forests in the Jike area have declined and it became necessary for rural and urban residents to conserve rural landscape including rural forests and valley lowlands (Figure 8).

Because the combination of rural forests and valley lowland in the Jike area were represented as a typical Japanese rural landscape, conservation activities of rural forests and valley lowlands have been practiced by farmers since the 1980s. An organization called the Jike Furusato Association, was originally formed by about

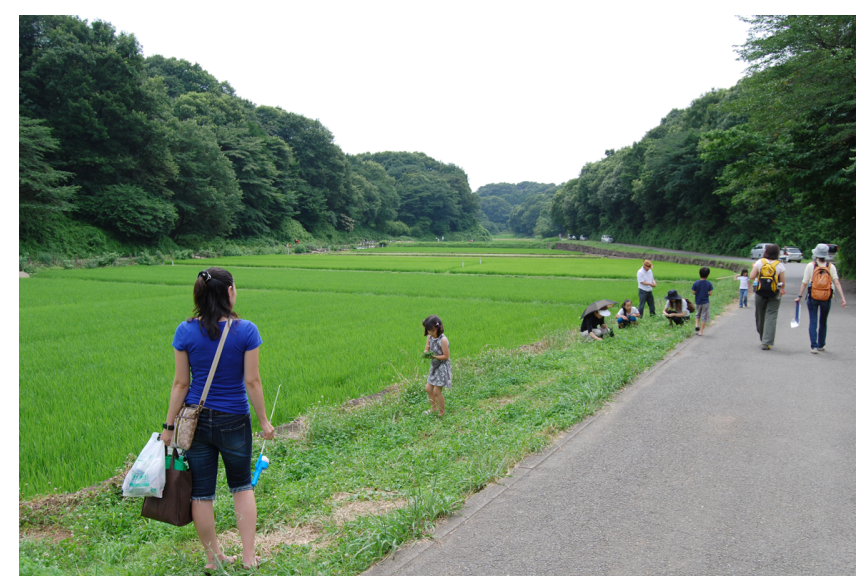

Figure 8. Rural landscape of the Jike area. Taken by the author, July 2009

thirty farms in the Jike area. As the background to this foundation, Yokohama city has been concerned about the drastic decrease of rural forests with the expansion of urban land use, and has taken rural forests of the Jike area on lease for the conservation of natural environment, rural landscape and leisure space. Yokohama city entrusted the management of rural forests in the Jike area to this association. At first, conservation activities of the association were limited within the rural forests entrusted from Yokohama city. Since the 1990s, however, this association has extended its conservation activities to valley lowlands and streams around rural forests (Figure 9), because these environmental components function as one ecological unit. Actually, rural forests provide water that flows down streams in valley lowlands, which in turn support biodiversity such as aquatic plants and insects, and irrigate paddy fields for rice cultivation. Generally speaking, it is important for the commodification of rural spaces to conserve rural landscape and ecosystems including forests, streams and farmlands.

In the Jike area, rural forests were traditionally used for producing compost, charcoal and firewood by rural residents, and the forest bed was maintained by farmers' activities such as collecting fallen leaves, and clearing the undergrowth and low branches. Since the 1970s, however, degradation of forests in this area due to less maintenance and management is a consequence of the shortage of agricultural labor force. Conservation activities of the Jike Furusato Association have maintained and managed such rural forests, saving these valuable ecosystems. It was becoming increasingly difficult for elderly farmers to conserve rural forests, streams and valley lowlands, so this association plays an important role in maintaining and managing local forests on a regular basis. Every year, this association has recruited support members who 


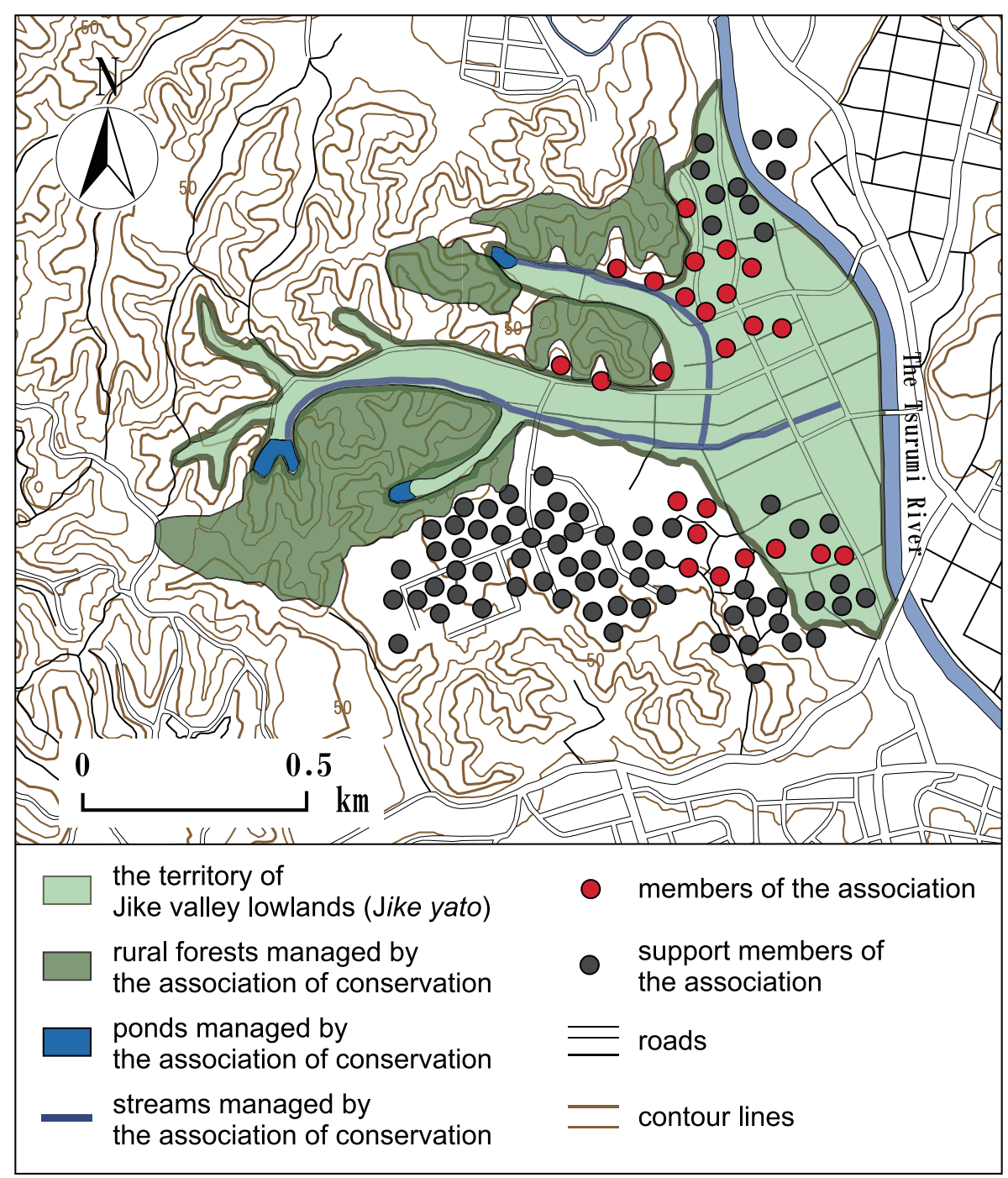

Figure 9. The conservation activities of rural forests, streams and valley lowlands in the Jike area. Sources: Field survey and interview.

are mainly urban residents and newcomers, as helpers of conservation activities. Support members of this association amount to about 80 households, living in and around the Jike area (Figure 9).

In terms of conservation activities, members and support members clear the forest undergrowth every summer, and collect fallen leaves every autumn. As a consequence, healthy green spaces and ecosystems have been maintained since the 1990s. Members also clean the streams to conserve habitats of fireflies, which are a typical indicator of a healthy environment and of successful conservation activities. Fireflies have been observed around streams every summer, so conservation activities have achieved obvious success. Conservation and maintenance activities in and around rural forests are guided by members of the group (farmers and rural residents), while support members (urban residents) participate in such activities as a means of recreation and as an expression of their love for their home area.
While rural residents take part in conservation activities with the aim of preserving rurality including landscape, communities and agriculture, urban residents take part in these activities as a way to understand natural environment, out of a yearning for rurality and in order to enjoy rural recreation. Although rural and urban residents have different motivations for conservation activities of rural forests in the Jike area, they are brought together by their common interest in rurality and natural environment. Actually, cooperation for activities of forest conservation and maintenance led to the improvement of the relationship between rural and urban residents, and is one of central establishments forming a node for the maintenance of rurality and the connection with urbanity. As a result of recreating and restructuring rurality, the familiar rural landscape has been maintained as a system of rural forests, streams and paddy fields. This rural landscape has begun to attracting many visitors as a space of rural tourism and recreation, so that recreating 
and restructuring rurality played a leading role in the commodification of rural spaces.

\section{The Sustainable Commodification of Rurality and Rural Space: Conclusion}

The decrease in rural forests has led to the decline of rural landscape in and around the Jike area, following the development of housing lots and the inflow of new urban residents to the outer suburbs. Urban and rural residents now co-exist in this formerly rural area, and the traditional rurality has tended to be lost with the inflow of urban residents and the decline of rural landscape. The traditional rurality consisted of farms, their community, their ecological bases such as farmlands and rural forests, and economic activities such as farming and produce selling. This rurality was based on the interrelationship among these elements. Although it was developed with the exclusive and strong relationship between farmers, it was disrupted by the inflow of urban residents, and rural landscape was damaged with the loss of ecological and socio-economic bases such as farmlands, rural forests and agricultural labor. Replacing the traditional rurality, urbanity has become dominant as the regional characteristic in and around the Jike area. Generally, urbanity consists of urban residents and their community, urban land use, urban economic activities. This urbanity is developed with the increase in urban residents, who commute to Tokyo metropolitan centre and only use this area as a bed town, without any sense of belonging. Following the development of urbanity, a part of rural land use has been replaced by urban land use. The increasing dominance of urban communities, urban land use and urban economic activities has contributed to weakening the rurality in and around the Jike area.

However, recent attempts at recreating rurality have been promoted by the conservation activities of rural forests. With the development of these activities, valley lowlands and streams around rural forests have been also conserved as parts of an ecological system, and paddy and upland fields have been maintained as the bases of agricultural activities. The maintenance of agricultural activities has led to the perpetuation of agricultural land use and rural communities in this area. Therefore, recreating rurality by means of conservation and maintenance of rural space and rural landscape translated into the preservation of a healthy environment and leisure space in Tokyo metropolitan suburbs. On the other hand, urban residents have demanded the amenity of residential environment since the 1990s, and conservation activities of rural forests increased their awareness of the value of rurality in the metropolitan suburbs. Although rural and urban residents consider conservation activities from different perspectives, their interests in rurality come together in the conservation of rural forests in their residential area. The relationship between rural and urban residents is developed in their cooperation for the conservation and maintenance of rural forests, which is one of the nodes or central establishments for connecting rurality to urbanity. According to Figure 10 which shows the framework of relationships between rurality and urbanity in the Jike area, mutual relationships among elements of urbanity and rurality developed through conservation activities as one of the nodes.

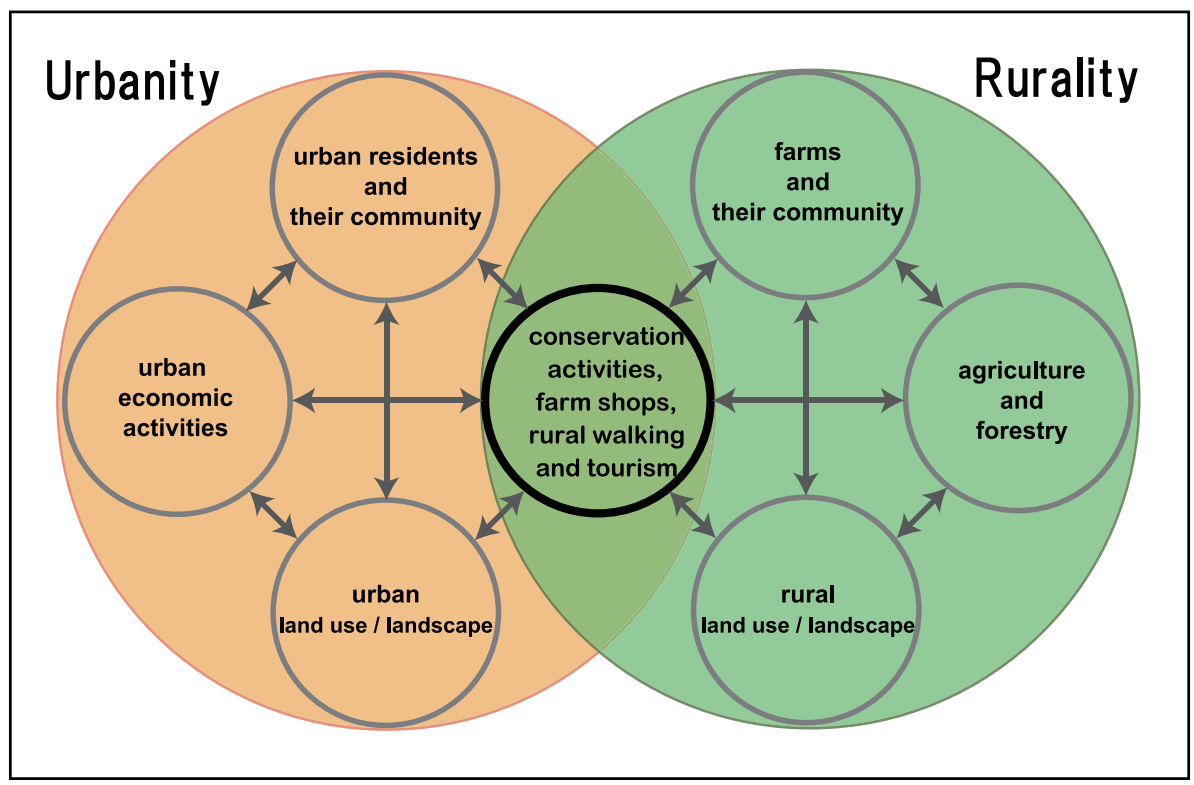

Figure 10. The framework of relationships between rurality and urbanity in the Jike area. 
This connection with urbanity leads to the sustainable development of rurality in this area.

With the recreation of rurality, rural landscape plays an important role in the commodification of rural space. Rural landscape in the Tokyo metropolitan suburbs is generally suitable for leisure and health-enhancing activities, because it is easily accessible for urban residents. Visitors are enjoying the rurality through walks, rural landscape observation, shopping for agricultural products and friendly exchanges with farmers. In spite of their advanced age, rural residents continue to cultivate crops such as "hama-yasai" and "hama-nashi" for visitors, and to preserve rural land use and landscape for themselves as well as visitors. In the process of recreating rurality, rural residents preserve their traditions and identity, their religion of rural life and the spirituality of the rural space. Urban residents, on the other hand, enjoy rural recreation, the understanding of natural environment, and satisfy their inner yearning for a sense of belonging. Although some plots of rural forests in the Jike area were on sale (either by farmers under tax pressure or for the construction of a large scale housing complex), most forests were managed for the conservation of natural and rural environment by the association of conservation activities. As shown in Figure 10, because these activities have become the node of rurality and urbanity, the conservation of rurality has been assured with the sustainable relationships between rurality and urbanity. The conservation of rurality leads to its commodification in rural spaces, which has played an important role in developing rurality-based tourism.

\section{Acknowledgements}

This study was partly supported by a Grant-in-Aid for Scientific Research (A) 2007-2009, "Human Geographical Study on the Commodification of Rural Spaces in Japan" (Representative: Akira TABAYASHI, Proposed Number 19202027), and a Grant-in-Aid for Scientific Research (C) 2008-2009, "Geographical Study on Creation of Greentrification and its Sustainability in the Urban Fringe" (Representative: Toshio KIKUCHI, Proposed Number 20500896).

\section{References}

Bowler, I. R., Bryant, C. R. and Cocklin, C. 2002. The sustainability of rural systems. London: Kluwer Academic Publishers.

Bryant, C. R. and Johnston, T. R. R. 1992. Agriculture in the city's countryside. London: Belhaven Press.

Bryant, C. R., Russworm, L. H. and McLellan, A. G. 1982. The city's countryside: Land and its management in the rural-urban fringe. London: Longman.

Cloke, P. 1993. The countryside as commodity: New rural spaces for leisure. In Leisure and the environment: Essays in honor of Professor J. A. Patmore, ed. S. Glyptis, 53-67. London: Belhaven Press.

Halfacree, K. 1995. Talking about rurality: Social representation of the rural as expressed by residents of six English parishes. Journal of Rural Studies 11: 1-20.

Ilbery, B. W. 1985. Agricultural geography. Oxford: Oxford University Press.

Kikuchi, T. 1994. Land use changes and its characteristics in the Auckland city's countryside, New Zealand: A case study of the Clevedon area, Manukau city. Journal of Geography 103: 377-397. (JE)

Kikuchi, T. 2002. Agricultural land use changes and their sustainability in the urban shadow of the Sydney metropolitan region, Australia: A case study of Castlereagh area, Penrith city. Journal of Geography 111: 81-99. (JE)

Kikuchi, T. and Moran, W. 1990. Land use changes and its characteristics in the Auckland metropolitan region, New Zealand: A case study of the East Tamaki area, Manukau city. Geographical Review of Japan 63A: 741-765. (JE)

Kikuchi, T. and Obara, N. 2004. Spatio-temporal changes of urban fringe in Tokyo metropolitan area. Geographical Reports of Tokyo Metropolitan University 39: 57-69.

Kikuchi, T. and Obara, N. 2005. Recreating of rurality around Totoro forest in the outer fringe of Tokyo metropolitan area: The spirituality of rurality. Geographical Reports of Tokyo Metropolitan University 40: 39-52.

Kikuchi, T. and Takatori, Y. 1998. Sustainability of agricultural land use changes in urban fringe: A case study of Chofu city, Tokyo metropolis. Geographical Reports of Tokyo Metropolitan University 33: 45-62.

Kikuchi, T. and Tsutsumi, J. 1998. Sustainability and changeability of agricultural land use in the peri-urban environment: A case study in a sericulture region in Maebashi city, central Japan. Quarterly Journal of Geography 50: 1-16. (JE)

Kikuchi, T., Obara, N. and Kishimoto, S. 2006. Recreating of rurality of suburban dairy farming region in the outer fringe of Tokyo Metropolis. Geographical Reports of Tokyo Metropolitan University 41: 61-73.

Kikuchi, T., Oishi, T. and Saitoh, R. 2002. Recreating of the rurality in the urban fringe of Tokyo metropolitan area: A case study of Kodaira city. Geographical Reports of Tokyo Metropolitan University 37: 93-102.

Liepins, R. 2000. Exploring rurality through "community": Discourses, practices and spaces shaping Australia and New Zealand rural "communities." Journal of Rural Studies 16: 325341.

Marsden, T. 1996. Rural geography trend report: The social and political bases of rural restructuring. Progress in Human Geography 20: 246-258.

Murdoch, T. and Pratt, A. 1993. Rural studies: Modernism, postmodernism and the "post rural." Journal of Rural Studies 9: 411-428. 
Takatori, Y. 1998. The location of farm shops and the sustainable mechanism of their existence in the Kanto district. In Sustainable rural systems in the context of global changes, ed. R. Epps, 124-131. Armidale, Australia: University of New England.
Takatori, Y. 2000. The multi-functional system of urban agriculture in the suburbs of Tokyo: A case study in the Nishi-Ooizumi area of Nerima ward, Tokyo. Journal of Geography 109: 401417. (JE)

(JE): written in Japanese with English abstract 